\title{
Guardados de um Artesão de Imagens: Estudo da trajetória de Claro Jansson e de suas crônicas visuais durante as primeiras décadas do século XX de Rafael Ginane Bezerra ${ }^{1}$
}

\author{
Celso Fernando Claro de Oliveira²
}

- Enviado em 21.11.2016

- Aprovado em 03.12.2016

A questão do distanciamento crítico entre um pesquisador e seu objeto de estudo permeia todos os campos de conhecimento. 0 interesse por um objeto de pesquisa pode ter origens diversas. Nesse sentido, é possível observar que muitos cientistas das áreas de humanidades voltam-se para objetos de pesquisa que fazem parte de seu cotidiano, tendo por base suas experiências prévias com o mesmo. Este é o caso da tese “Guardados de um Artesão de Imagens: Estudo da trajetória de Claro Jansson e de suas crônicas visuais durante as primeiras décadas do século XX", de Rafael Ginane Bezerra.

Parte dessa relação pesquisador-objeto é abordada pelo autor à conclusão de seu trabalho: nascido em Porto União, uma das cidades mais emblemáticas da região do Contestado, Bezerra conviveu com o tema desde a infância, tomando parte no processo de construção de identidades realizado pelos habitantes da área em que o referido conflito se desenrolou. A partir de suas experiências em meio a personagens históricos, relatos, memórias e imagens, o sociólogo nutriu grande interesse pela produção de Claro Jansson, imigrante sueco que se estabeleceu no Brasil ao final do século XIX e desenvolveu uma

\footnotetext{
1 Tese de Doutorado em Sociologia defendida no Programa de Pós-graduação em Sociologia da UFPR no ano de 2009 realizado sob a orientação da Professora Doutora Ana Luisa Fayet Sallas. Versão na íntegra disponível em file://C:/Users/Ana/Downloads/TESE\%20RAFAEL\%20GINANE\%20BEZERRA.pdf. Acesso 21.set.2016.

2 Doutor em História pela Universidade Federal de Santa Catarina. Professor colaborador da Universidade Tecnológica Federal do Paraná (UTFPR) - Câmpus Curitiba. Email: celsooliveira88@gmail.com
} 
carreira notável como fotógrafo. Entre os muitos momentos que Jansson registrou ao longo de sua atuação profissional, encontram-se imagens do cotidiano da região e de diversas situações relacionadas ao próprio conflito.

0 objetivo do trabalho de Bezerra é esmiuçar a "trajetória" de Jansson por meio dos documentos fotográficos produzidos em diferentes recortes espaço-temporais, contando com o apoio de fontes complementares - tais como correspondências assinadas pelo fotógrafo e reportagens das publicações que divulgaram seus trabalhos. Trata-se de um trabalho de grande relevância, uma vez que Jansson, conforme ressalta o próprio Bezerra, já foi tema de obras biográficas romantizadas, que contribuíram para difundir uma imagem idealizada do fotógrafo como profissional itinerante ou pioneiro do fotojornalismo brasileiro.

Por outro lado, a empreitada proposta por Bezerra não foi uma tarefa simples: a ausência de documentos em alguns períodos da vida de Jansson constitui um obstáculo à construção da trajetória; enquanto as diferentes formas que suas fotografias foram (re)apropriadas ao longo do tempo e os relatos contraditórios a respeito de Jansson revelam um notável choque de informações. Bezerra, por sua vez, demonstra aptidão como pesquisador e utiliza-se de tais 'entraves' para tecer análises sobre a imagem do fotógrafo e a recepção de sua obra.

A tese é dividida em seis seções, sendo que a primeira serve de introdução ao trabalho. Neste capítulo, Bezerra apresenta seus interesses e objetivos com a pesquisa, bem como, um breve debate teórico inicial que será desenvolvido adiante. Cabe destacar o esforço em desmistificar a imagem do fotógrafo - é constante a preocupação do autor em compreender Claro Jansson como um homem inscrito em um contexto específico, inserido em uma rede de relações políticas e sociais que afetam sua trajetória.

Desse modo, não se trata de um endeusamento do personagem (caminho comumente seguido pelos escritos a respeito de Jansson), mas de entendê-lo como um agente histórico 
influenciado e capaz de transformar o ambiente a sua volta ${ }^{3}$. Essa dinâmica é essencial para que o autor possa analisar as fotografias, como é explicitado na seguinte passagem:

[0 objetivo do trabalho] antes de qualquer coisa, [é] de reconstruir a sua trajetória para resgatar a legibilidade de suas fotografias e, a partir disto, verificar o que a articulação entre ambas e o seu contexto social de origem revela. [...] Se a natureza indiciária da fotografia marca o seu vínculo com o real, este vínculo é codificado pela atuação do fotógrafo, pela posição que ocupa no espaço social, por suas escolhas técnicas, estéticas e ideológicas ${ }^{4}$.

É interessante notar que o autor busca realizar tal operação analítica logo à "Introdução", valendo-se do exemplo da fotografia “Casamento em Três Barras, 1918”. A partir do documento, Bezerra apresenta raciocínios interessantes sobre como se organizava a sociedade daquele núcleo populacional ao início do século $\mathrm{XX}$, bem como, o papel de Jansson nessa mesma sociedade. Esse procedimento será cotejado ao longo dos capítulos seguintes do trabalho, servindo para corroborar os intuitos do pesquisador.

Embora as análises realizadas por Bezerra ao longo da tese sejam ricas em detalhes e informações - evidenciando seu cuidado na leitura das fontes e da sociedade que as legou -, o debate teórico-metodológico, apresentando no segundo capítulo, é elaborado de maneira truncada. Partindo da evidente preocupação em apresentar um "estado da arte" dos estudos de fotografia nas humanidades, Bezerra dialoga com uma série de autores, porém, boa parte das discussões não é entrelaçada de forma clara, especialmente pelo fato de as referências utilizadas, por vezes, apresentaram preocupações distintas com relação ao objeto. Basta

${ }^{3}$ Convém ressaltar que Bezerra reconhece as particularidades da trajetória de Jansson e sua relação com diferentes momentos históricos, tendo fotografado uma série de acontecimentos históricos marcantes. BEZERRA, Rafael Ginane. Guardados de um Artesão de Imagens: Estudo da trajetória de Claro Jansson e de suas crônicas visuais durante as primeiras décadas do século XX. Tese [Doutorado em Sociologia]. Curitiba: Universidade Federal do Paraná, 2009, p. 72-73.

${ }^{4}$ BEZERRA, Op. Cit., p. 19. 
tomar como exemplo os argumentos apresentados pelo culturalista francês Philippe Dubois e pela historiadora brasileira Ana Maria Mauad, ligada à História Social55.

Os debates do segundo capítulo acabam por se concentrar nas principais referências teóricas de Bezerra: os sociólogos alemães Georg Simmel, Siegfried Kracauer e Norbert Elias. Os três estudiosos apresentam aproximações em suas abordagens a respeito dos ideais de "modernidade" e "civilização" ao início do século XX, todavia, estes aparecem relacionados apenas de forma indireta e pouco clara ao objeto da pesquisa. Não deixa de ser curioso que os escritos dos dois primeiros autores já tenham passado por uma série de avaliações e receberam críticas notáveis que não são apontadas por Bezerra. Por fim, cabe mencionar que muitos conceitos não são apresentados de forma adequada, como é o caso do termo "cultura", empregado em diferentes momentos e relacionado a vários autores citados ao longo da tese.

Apesar dos problemas destacados, Bezerra dá continuidade ao trabalho realizando interessantes análises a respeito das fontes sobre as quais se debruça. A terceira seção trabalha o início da trajetória de Jansson no Brasil, desde sua chegada ao país às primeiras experiências com fotografia. Nesse capítulo, as cartas que o emigrante escreveu para familiares que permaneceram na Suécia servem como os principais documentos na análise de sua trajetória. Entre os temas abordados, destacam-se as primeiras ocupações profissionais; as andanças pelo sul do Brasil e as regiões de produção de erva-mate na Argentina; e o despertar do interesse pela fotografia. Bezerra tece uma análise bastante perspicaz a respeito do último elemento:

Janson aprendeu a fotografia de forma autodidata, pensando em se comunicar melhor com a família que permanecera na Suécia. Isso se justifica não apenas através das cartas, mas da falta de documentos que comprovem que ele pensou em exercer profissionalmente o ofício [de fotógrafo] desde que adquiriu a primeira câmera. É

\footnotetext{
${ }^{5}$ Acredito que as propostas de Mauad e outros pesquisadores ligados à História Social e ao materialismo histórico poderiam oferecer um respaldo mais sólido para Bezerra ao longo de seu trabalho. Talvez um dos debates mais refinados para se pensar as relações entre "arte" (no caso, a fotografia) e "sociedade" (o conjunto de instituições e relações sociais que envolvem a produção artística) seja o trabalho da socióloga marxista Janet Wolff. Conferir: WOLFF, Janet. The Social Production of Art. Londres e Basingstoke: The MacMillan Press, 1981.
} 
tentando mostrar aos familiares um pouco de seu trabalho e seu cotidiano que Janson começa a fazer as primeiras séries de fotos ${ }^{6}$.

A quarta seção é dedicada à análise da trajetória de Jansson na região do Contestado nas primeiras décadas do século XX. Trata-se da parte mais interessante do trabalho, uma vez que as análises se mostram bastante apuradas, especialmente no que diz respeito ao estudo da relação entre o fotógrafo e as organizações sociais no espaço em questão7. Dois são os temas principais das imagens produzidas por Jansson naquele período: as iniciativas da Southern Brazil Lumber \& Colonization Company, empresa do ramo madeireiro que pertencia ao estadunidense Percival Farquhar; e a escalada de tensões que desembocou na Guerra do Contestado.

Bezerra afirma que Jansson construiu "crônicas visuais" a respeito de ambos os temas. No caso do empreendimento de Farquhar, as fotografias teriam por objetivo destacar uma espécie de ímpeto modernizador e civilizatório, capaz de elevar o Brasil ao patamar das grandes nações daquele período. 0 amplo volume de produção e a grandiosidade da estrada de ferro construída para escoar os produtos constituem alguns dos temas centrais dessas fotografias. Entretanto, as imagens de Jansson também revelam informações sobre os hábitos e o cotidiano dos funcionários da companhia, incluindo movimentos reivindicatórios - como o caso de uma greve deflagrada em 1917.

Mesmo não tendo participado diretamente de muitos episódios da Guerra do Contestado, Jansson também produziu "crônicas visuais" sobre os envolvidos no conflito. Bezerra assinala uma importante divisão no tratamento dado aos oponentes no campo de batalha. Ao registrar as tropas de oficiais ou os encarregados da defesa da Lumber, as fotografias de Jansson evocam ideais como "ordem" e "cumprimento de dever", de modo que muitas de suas imagens foram posteriormente (re)apropriadas para a criação de uma representação positiva dos militares por parte de governos federais e estaduais. Nesse

\footnotetext{
${ }^{6}$ BEZERRA, Op. Cit., p. 68.

${ }^{7} \mathrm{O}$ contexto é abordado com base em estudos de renome sobre o Contestado, assinados por autores como Paulo Pinheiro Machado e Maurício Vinhas de Queiroz.
} 
sentido, Bezerra destaca que imagens cujas interpretações eram consideradas contraditórias pelas forças oficiais foram preteridas pelas autoridades militares. Os sertanejos envolvidos com o movimento messiânico, por sua vez, têm destacado o que poderia se definir, grosso modo, como um caráter de selvageria. Nas fotografias, esses homens e mulheres emergem como bárbaros que se colocam contra o processo de modernização capitaneado pelo governo republicano.

Apesar de esse breve panorama parecer corroborar a ideia de que Jansson ofereceu respaldo a uma espécie de "discurso oficial", Bezerra é bastante arguto em assinalar que o fotógrafo deixou poucos registros escritos sobre as intenções e motivos que o levaram a produzir boa parte de sua obra. Somando esse debate às constantes (re)apropriações das referidas imagens por diferentes instituições e meios de comunicação em diferentes momentos, o autor destaca que não há interpretações fáceis sobre a maioria dos registros legados por Jansson.

Por outro lado, Bezerra salienta que a atuação do fotógrafo deve ser analisada à luz de sua inserção na sociedade daquele período. À época do desenvolvimento dos empreendimentos da Lumber, Jansson administrava um bem-sucedido estúdio fotográfico, além de ter tomado parte em outras atividades profissionais, como o comércio de erva-mate. Fluente em diversos idiomas, atuou como juiz de paz e chegou a receber o posto de Tenente da Guarda Nacional. Esse capital social permitiu a Jansson transitar com notável desenvoltura entre os diferentes estratos e instituições sociais da região à época, influenciando seu trabalho como fotógrafo.

A energia empregada pelo autor no capítulo quarto foi deixada a desejar na seção seguinte. 0 quinto segmento é bastante curto se comparado aos demais e abarca um período cronológico consideravelmente extenso, dedicando-se a analisar a trajetória de Jansson após ter deixado a região do Contestado para estabelecer-se em Itararé (SP). Embora Bezerra se volte, nesse capítulo, para a análise de fotografias emblemáticas, como a chegada de Getúlio Vargas à cidade durante a Revolução de 1930 ou os embates da Revolução Constitucionalista de 1932, conduz análises demasiado apressadas e com menor nível de detalhamento. Fica a impressão que faltou fôlego para que o autor continuasse a explorar a trajetória de Jansson. 
Suas reflexões mais interessantes dizem respeito à recorrência de temas das fotografias, bem como a alguns apontamentos sobre as trocas de cartas entre Jansson e seus parentes na Suécia.

A sexta e última parte do trabalho serve como conclusão à pesquisa. Bezerra recupera as mais relevantes hipóteses na fundamentação do trabalho e expõe suas considerações finais. O estudo sobre a trajetória de Jansson tem sua importância: problematizar, compreender e desmistificar tanto o trabalho, quanto a trajetória do fotógrafo; bem como, avaliar a recepção e as apropriações de seus registros pela imprensa e diferentes instituições sociais. Por outro lado, algumas questões permanecem em aberto - diante do grande cuidado na reconstituição da trajetória inicial de Jansson no Brasil, por exemplo, torna-se gritante uma investigação mais abrangente de seus últimos anos de vida e atuação profissional. Essas lacunas, por sua vez, oferecem oportunidades para o desenvolvimento de futuras pesquisas.

Referências:

BEZERRA, Rafael Ginane. Guardados de um Artesão de Imagens: Estudo da trajetória de Claro Jansson e de suas crônicas visuais durante as primeiras décadas do século XX. Curitiba: Doutorado em Sociologia da UFPR, 2009.

WOLFF, Janet. The Social Production of Art. Londres e Basingstoke: The MacMillan Press, 1981. 